\title{
Design and investigations of MPPT strategies for a wind energy conversion system based on doubly fed induction generator
}

\author{
Bouchaib Rached, Mustapha Elharoussi, Elhassane Abdelmounim \\ Laboratory of Signal Analysis and Information Processing, FST Settat, Hassan $1^{\text {st }}$ University, Morocco
}

\begin{tabular}{l} 
Article Info \\
\hline Article history: \\
Received Jul 30, 2019 \\
Revised Mar 12, 2020 \\
Accepted Mar 26, 2020 \\
\hline
\end{tabular}

\section{Keywords:}

Doubly fed induction generator Fuzzy logic controller MPPT

Pitch angle control

RST controller

\begin{abstract}
The purpose of this work is to design and to discuss various strategies to optimize the production of a wind energy conversion chain based on the doubly fed induction generator (DFIG), by capturing the maximum power at the wind turbine, using maximum power point tracking (MPPT) and pitch control. The proposed controls allow the generator to monitor the optimal operating points of the turbines regardless of wind speed variations, system parameters disturbance, and parameters variation. Simulation of WECS based on a $1.5 \mathrm{MW}$ wound rotor induction generator under MATLAB/SIMULINK is carried out using the PI controller (PIC), RST controller and fuzzy logic controller (FLC). Analysis and comparisons are made for different operating scenarios: Reference tracking, robustness under variable wind speed conditions and parameters variation. The application of FLC provides a very interesting outcome for the robustness and the dynamic challenges.
\end{abstract}

Copyright $\odot 2020$ Institute of Advanced Engineering and Science. All rights reserved.

\section{Corresponding Author:}

Bouchaib Rached,

Physics and Engineering Science Department,

Hassan $1^{\text {st }}$ University,

Settat, Morocco.

Email: bouchaib.rached@gmail.com

\section{INTRODUCTION}

In recent years, the environmental and/or ecological context has become an important or even predominant factor. Indeed, the increasing consumption of electric energy in the world, the limitation and the progressive depletion of fossil fuels (oil, gas, coal...) characterized by the emissions of carbon dioxide produced during their combustion, on the one hand, and the risk of nuclear power plants (uranium radiation) with the production of radioactive residues that are difficult to treat for the nuclear power, on the other hand, are very real problems that have pushed researchers to exploit other sources of sustainable and more environmentally friendly energy. These substitute means are the "renewable energies" [1,2].

The main forms of renewable energies are hydropower, solar thermal, photovoltaic and wind power, as well as biomass and geothermal energy. Among all renewable energies contributing to electricity production, wind energy was the first to be exploited. It is clearly in a good position, not as a replacement for conventional sources, but as a complementary alternative to nuclear energy. Currently, the vast majority of wind energy conversion systems use doubly fed induction generator (DFIG), which give the advantage of better exploiting wind resources in different wind conditions thanks to its variable-speed operation and the use of static power converters associated with control systems [3].

A description of the different components of the WECS based on a DFIG is illustrated in Figure 1. It can be divided into two main parts. The mechanical part which is composed of the turbine, the gearbox and the transmission shaft. Then, the electrical part which is composed of the DFIG whose stator is attached directly to the electrical grid, as long as the rotor is linked to the grid through two static bidirectional power converters. To optimize the electrical power production of wind turbines, different strategies and control 
designs were applied to wind turbines in each of the operating zones such as the MPPT control strategy and pitch angle control to extract the maximum power.

With the growing interest in wind power generation through DFIG, several control methods have been developed. In general, a control system aims at monitoring a system to obtain a correct functioning of the latter. The control allows the system to track the desired response for a given input and to reject the effects of disturbances. Unfortunately, when system modelling is difficult, the design of the control system can be very complex. This difficulty is caused by strong non-linearities, parametric variations or inaccuracies in the internal variables. But in spite of this, several methods have been found to deal with the problem, such as sliding mode control (SMC) [4-6], backstepping control (BC) [7-10], non-linear control by static or dynamic state feedback [11]. All these techniques have difficulty in that their design is strongly dependent on the system model. These difficulties have led in recent years to the development of new control techniques based on artificial intelligence (neural networks, fuzzy logic, genetic algorithms...) to control these systems.

In this context, this work focuses on the control of a DFIG-based wind energy conversion system (WECS), emphasizing the use of fuzzy logic control and understanding it in conjunction with conventional PI and RST-based vector control. Tests of the adapted control strategies will be carried out under the Matlab/Simulink software environment. The results of the various tests performed in numerical simulation as well as the tests will be presented and interpreted.

The paper is structured in the following way: Section 2 will be devoted to system description and dynamic model. The control strategies are carefully elaborated in section 3 , followed by simulation results in section 4 . We will terminate this work with a brief conclusion.

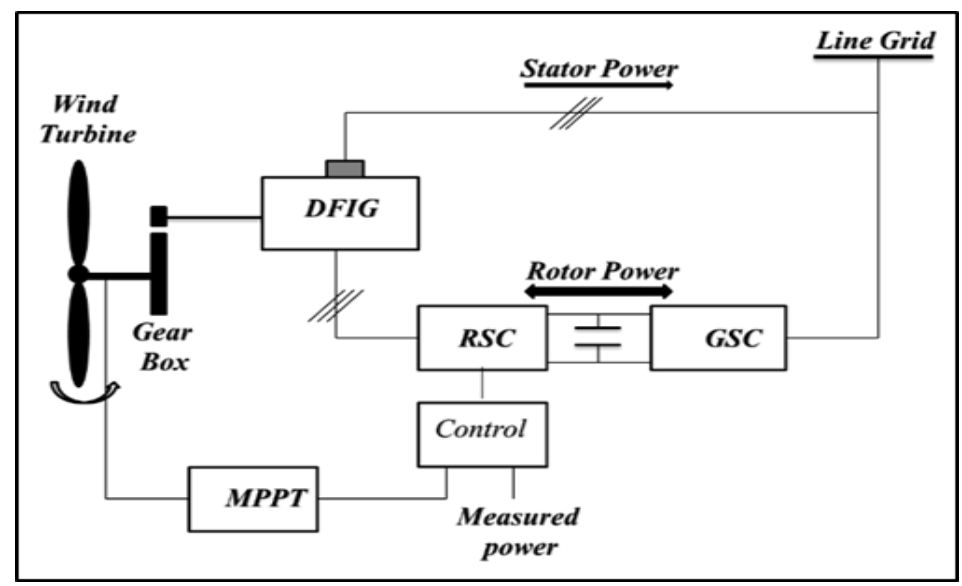

Figure 1. The DFIG-based wind conversion chain

\section{SYSTEM DESCRIPTION AND DYNAMIC MODEL}

\subsection{Wind turbine}

The aerodynamic torque, which is converted by a wind turbine, is expressed as [12-14]:

$$
T_{\text {aero }}=\frac{P_{\text {aero }}}{\Omega_{t}}=\frac{1}{2} \cdot C_{P}(\lambda, \beta) \cdot \rho \cdot S \cdot \frac{V_{\text {wind }}^{3}}{\Omega_{t}}
$$

where $C_{P}(\beta, \lambda)$ is the power coefficient, $\lambda$ is defined by: $\lambda=\frac{\Omega_{t} \cdot R_{\text {blade }}}{V_{\text {wind }}}$, and is the angle of blade orientation, $\Omega_{t}$ is the Rotational speed of the turbine, $V_{\text {wind }}$ is the wind speed, and $S$ is the area swept by the pales of the turbine. The dynamic of the wind turbine is a function of the mechanical torque $\left(T_{m}\right)$, the total inertia $(\mathrm{J})$, and the coefficient of total friction $(\mathrm{K})$. It is given by:

$$
N_{G}=\frac{\Omega_{m}}{\Omega_{t}} \quad, \quad T_{m}=\frac{T_{\text {aero }}}{N_{G}} \quad \text { and } \quad J \cdot \dot{\Omega}_{m}=T_{m}-K \cdot \Omega_{m}-T_{e m}
$$




\subsection{DFIG model}

The equations describing the functioning of DFIG are written as follows [15-17]:

Electrical equations

$$
\left\{\begin{array} { l } 
{ V _ { s d } = R _ { s } I _ { s d } + \frac { d } { d t } \Phi _ { s d } - \omega _ { s } \Phi _ { s q } } \\
{ V _ { s q } = R _ { s } I _ { s q } + \frac { d } { d t } \Phi _ { s q } + \omega _ { s } \Phi _ { s d } } \\
{ V _ { r d } = R _ { r } I _ { r d } + \frac { d } { d t } \Phi _ { r d } - \omega _ { r } \Phi _ { r q } } \\
{ V _ { r q } = R _ { r } I _ { r q } + \frac { d } { d t } \Phi _ { r q } + \omega _ { r } \Phi _ { r d } }
\end{array} \quad \text { and } \left\{\begin{array}{l}
\Phi_{s d}=L_{s} I_{s d}+M I_{r d} \\
\Phi_{s q}=L_{s} I_{s q}+M I_{r q} \\
\Phi_{r d}=L_{r} I_{r d}+M I_{s d} \\
\Phi_{r q}=L_{r} I_{r q}+M I_{s q}
\end{array}\right.\right.
$$

Powers Expressions

$$
\begin{aligned}
& \left\{\begin{array} { l } 
{ P _ { s } = v _ { s d } \cdot I _ { s d } + v _ { s q } \cdot I _ { s q } } \\
{ Q _ { s } = v _ { s q } \cdot I _ { s d } - v _ { s d } \cdot I _ { s q } }
\end{array} \text { and } \quad \left\{\begin{array}{l}
P_{r}=v_{r d} \cdot I_{r d}+v_{r q} \cdot I_{r q} \\
Q_{r}=v_{r q} \cdot I_{r d}-v_{r d} \cdot I_{r q}
\end{array}\right.\right. \\
& T_{e m}=p M\left(I_{r d} I_{s q}-I_{r q} I_{s d}\right)
\end{aligned}
$$

\section{CONTROL STRATEGIES}

\subsection{Tracking of the maximum power point of the proposed wind system}

The objective of this part is to develop an MPPT strategy for optimal energy transfer in DFIG-based wind energy systems.

\subsubsection{MPPT based on PI controller}

The proposed strategy controls the speed ratio $\lambda$ in such a way that it can be optimal ( $\lambda_{\text {opt }}$ ), and therefore the torque is adjusted to an optimal value $T_{o p t}$ at which the power coefficient is maximum $\left(c_{P M A X}\right)[18]$, which is given by $(6)$ :

$$
T_{o p t}=k_{o p t} \cdot \Omega_{m}^{2} \text { where, } K_{o p t}=\frac{1}{2} \cdot \rho \cdot \pi \cdot R_{\text {blade }}^{5} \cdot \frac{C_{P M A X}}{\lambda^{3}{ }_{o p t}}
$$

The studied PI control is illustrated in Figure 2.

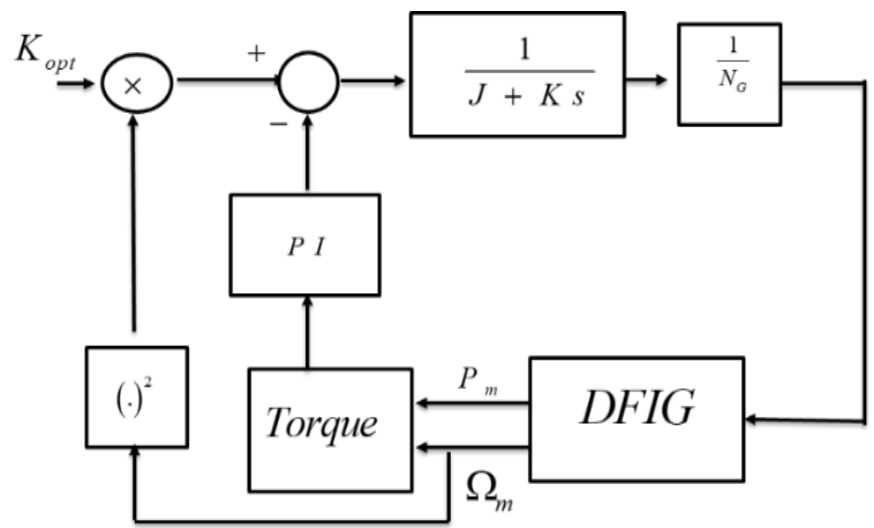

Figure 2. Diagram of the MPPT based on PI controller 


\subsubsection{MPPT based on RST controller}

The RST controller is based on the pole placement theory by specifying an arbitrary stability polynomial $\mathrm{D}(\mathrm{p})$ and computing $\mathrm{S}(\mathrm{p})$ and $\mathrm{R}(\mathrm{p})$ according to Bezout's equation [19].

$$
D=A S+B R \text { with }: \operatorname{deg}(D(p))=\operatorname{deg}(A(p))+\operatorname{deg}(S(p))
$$

The structure of the MPPT based on RST controller is depicted in Figure 3 [20].

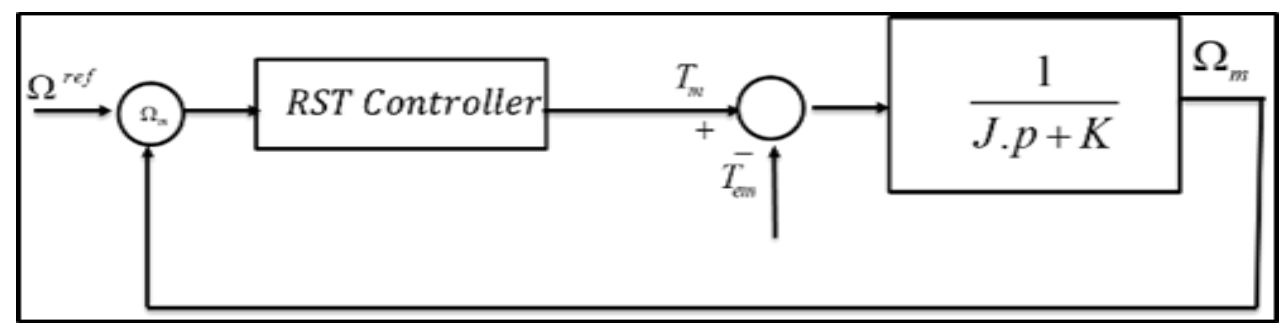

Figure 3. Diagram of the MPPT based on RST controllers

\subsubsection{MPPT based on fuzzy logic controller}

Fuzzy logic control makes it possible to imitate human reasoning by harnessing the diverse information collected in linguistic forms. It was developed by Zadeh in 1965 from the theory of fuzzy subsets and has the advantage of tolerating the uncertainty of the model and compensating its effect. The method presented below consists of combining the $\mathrm{P} \& \mathrm{O}$ algorithm with a fuzzy controller by taking into account the direction of variation of the disturbances. According to Figure 4, we have:

a. if a positive variation in Speed has caused a positive variation in Power, a positive variation in speed must be added;

b. if a negative variation in Speed has caused a positive variation in Power, a negative variation in speed must be added;

c. if a negative variation in Speed has caused a negative variation in Power, a negative variation in speed must be added;

d. if a positive variation in Speed has caused a negative variation in Power, a positive variation in speed must be added.

In summary, this method is detailed in the Table 1.

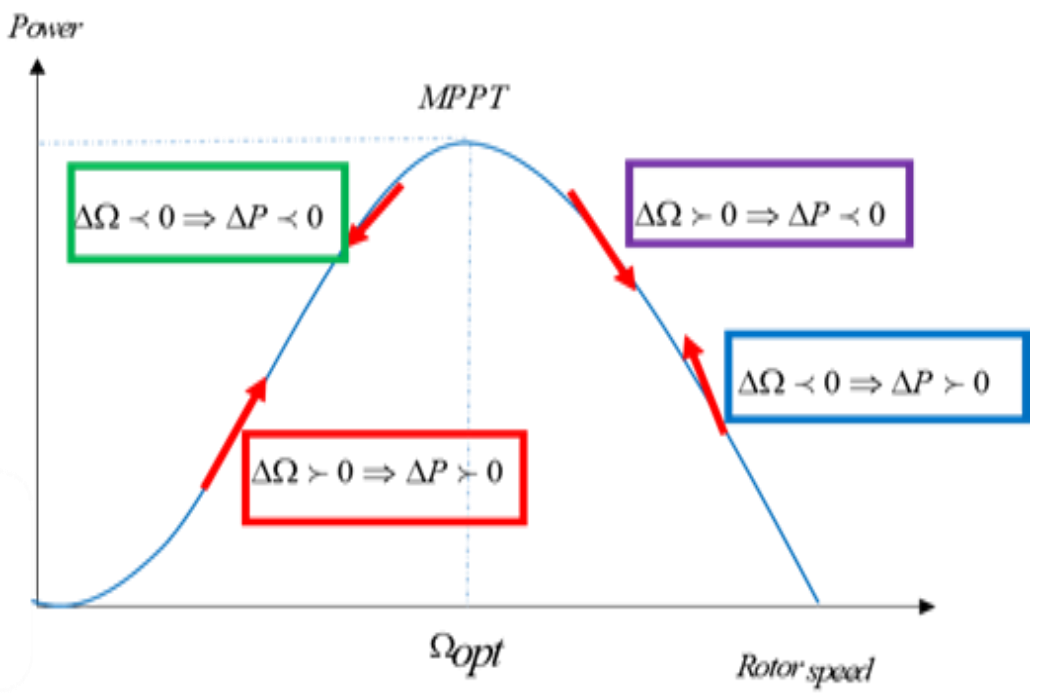

Figure 4. MPP tracking method 
Table 1. MPP tracking

\begin{tabular}{|c|c|c|c|c|c|c|c|c|}
\hline \multicolumn{9}{|c|}{$E$} \\
\hline \multirow{8}{*}{$\mathrm{DE}$} & & NB & $\mathrm{NM}$ & $\mathrm{NS}$ & $\mathrm{AZ}$ & PS & $\mathrm{PM}$ & PB \\
\hline & NB & $\mathrm{NB}$ & NB & NB & NB & NM & NS & $\mathrm{AZ}$ \\
\hline & NM & NB & NB & NB & NM & NS & $\mathrm{AZ}$ & PS \\
\hline & NS & NB & NB & NM & NS & AZ & PS & $\mathrm{PM}$ \\
\hline & $\mathrm{AZ}$ & NB & NM & NS & $\mathrm{AZ}$ & PS & PM & PB \\
\hline & PS & NM & NS & $\mathrm{AZ}$ & PS & $\mathrm{PM}$ & PB & PB \\
\hline & PM & NS & $\mathrm{AZ}$ & PS & PM & PB & PB & PB \\
\hline & PB & $\mathrm{AZ}$ & PS & PM & $\mathrm{PB}$ & PB & PB & PB \\
\hline
\end{tabular}

To implement this algorithm in a fuzzy controller, we used a Mamdani model as presented in Figure $5[1,15,21]$. The proposed controller has two inputs: the variation in DFIG power and the variation in rotational speed, and only one output, which is the optimal speed variation that ensures maximum aerodynamic efficiency. These variables are defined during one sample time. These variables are commonly fuzzified by symmetrical triangular membership functions. The fuzzy sets are defined as follows: NB: Negative Big; NM: Negative Medium; NS: Negative Small; AZ: About Zero; PS: Positive Small; NM: Positive Medium; PB: Positive Big. The fuzzy rules, for determining the output variable of the controller as a function of input variables are grouped in Table 1.

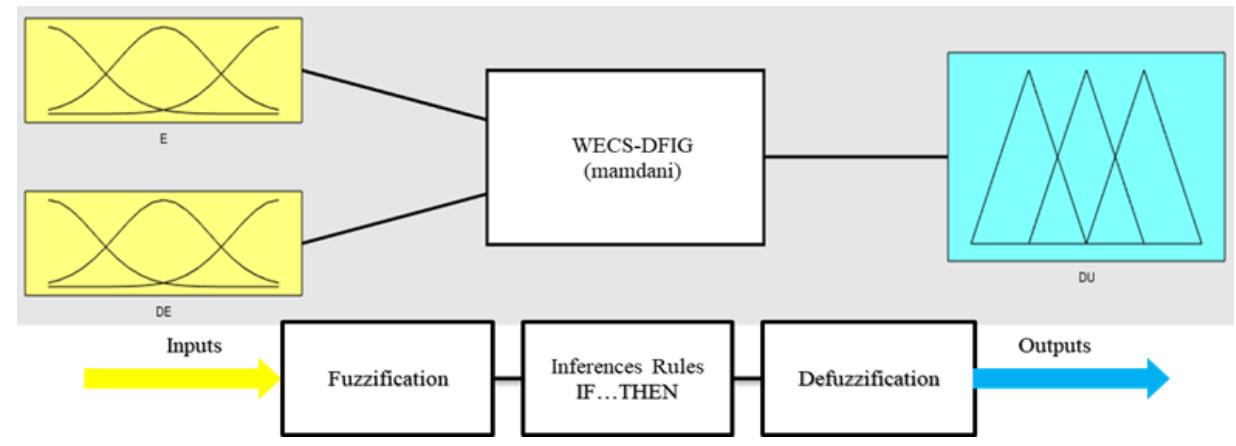

Figure 5. Block diagram of fuzzy control

\subsection{Pitch angle control strategies}

According to (1), the wind power captured by a turbine is proportional to the cube of the wind speed. There is a wind speed from which the mechanical power transmitted by the turbine is greater than the nominal power of the electrical machine. Various system elements are sized according to the loads, rotation speed and powers corresponding to this wind speed. These elements cannot support values exceeding certain limits. It is, therefore, necessary to limit the power captured by the turbine when the wind becomes too strong [22].

\subsubsection{Pitch angle control based on PI controller}

The value of the pitch angle $\beta$ varies between $0^{\circ}$ and $90^{\circ}$ to limit the mechanical power at its rated value. We will use a method based on the control of the generator power. As described in Figure 6, two PI controllers were used. The first PI to generate the reference pitch angle $\beta$ ref and the second regulator to control the error between $\beta$ ref and $\beta$. The same approach is followed to control the Pitch angle using RST controllers.

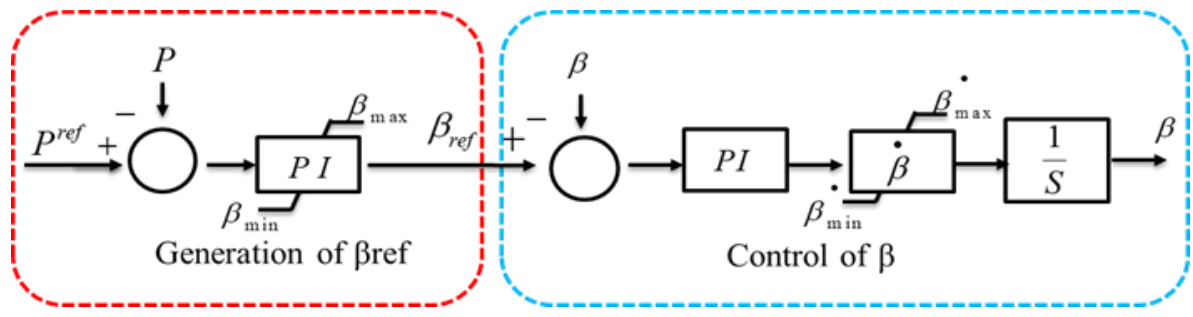

Figure 6. Pitch angle control using a PI controller 


\subsubsection{Pitch angle control based on fuzzy logic controller}

In this part, the fuzzy logic method without the wind speed measurement, as shown in Figure 7 , is used. The rotation speed of the generator, the active power tracking error and the variation of the tracking error are the inputs of the control. The output of the control is the reference pitch angle $\beta$ ref.

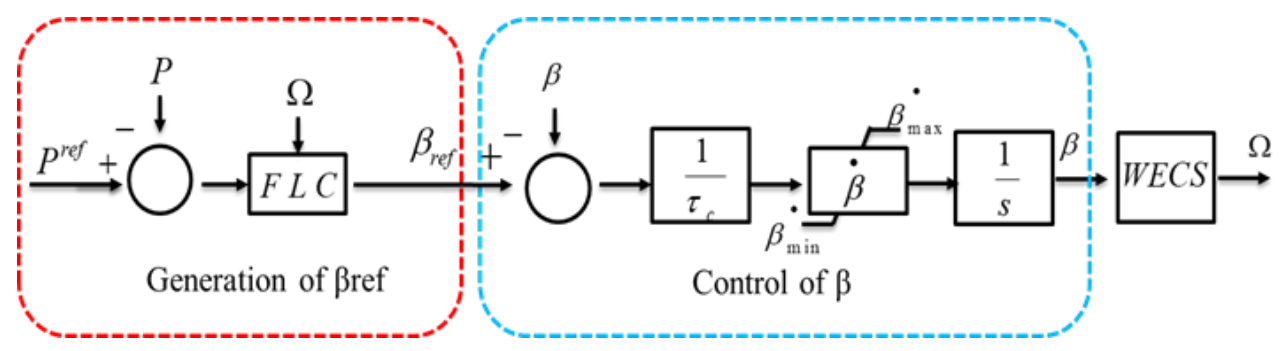

Figure 7. Pitch angle control using FLC

\subsection{Rotor side converter control}

The purpose of controlling this converter is to control the stator's powers.

\subsubsection{Vector control of DFIG}

The two phases modelling of the machine is used. The reference frame $(d-q)$ is oriented to align the axis d with the stator flux $[15,16,23,24]$. The (3) becomes:

$$
\phi_{S q}=0 \Leftrightarrow \phi_{S}=\phi_{S d} \text { and }\left\{\begin{array}{c}
V_{s d}=0 \\
V_{s q}=\omega_{s} \Phi_{s d}=V_{s}
\end{array}\right.
$$

So, we can write : $\left\{\begin{array}{c}\Phi_{S d}=L_{S} I_{S d}+M I_{r d} \\ \Phi_{S q}=L_{S} I_{S q}+M I_{r q}=0\end{array}\right.$

The adjustment of the equations (4) and (9) to the chosen axis system and the simplifying assumption considered in this case gives:

$$
\left\{\begin{array} { c } 
{ P _ { S } = - V _ { S } \frac { M } { L _ { S } } I _ { r q } } \\
{ Q _ { S } = \frac { V _ { S } \Phi _ { S } } { L _ { S } } - \frac { V _ { S } M } { L _ { S } } I _ { r d } \text { and } }
\end{array} \left\{\begin{array}{l}
P_{r}=g V_{S} \frac{M}{L_{S}} I_{r q} \\
Q_{r}=g \frac{V_{S} M}{L_{S}} I_{r d}
\end{array}\right.\right.
$$

Thus, power control is obtained by adjusting the rotor currents $\mathrm{d}$ and q:

$$
\left\{\begin{array}{c}
v_{r d}=R_{r} I_{r d}-L_{r} \omega_{r} \sigma I_{r q}+L_{r} \sigma \frac{d I_{r d}}{d t} \\
v_{r q}=R_{r} I_{r q}+L_{r} \omega_{r} \sigma I_{r d}+\frac{M \omega_{r}}{L_{s}} \Phi_{s d}+L_{r} \sigma \frac{d I_{r q}}{d t}
\end{array}\right.
$$

If $\mathrm{F}$ is the model of the process, the current control loop is shown in (12) and (13).

$$
F(s)=\frac{I_{r d}(s)}{V_{r d}^{r}(s)}=\frac{I_{r q}(s)}{V_{r q}^{r}(s)}=\frac{V_{S} M}{R_{r} L_{s}+s L_{s} L_{r} \sigma}
$$




$$
\text { and }\left\{\begin{array}{c}
e_{d}=g \omega_{s} \frac{M}{L_{S}} \phi_{s} \\
e_{q}=\frac{V_{S} R_{r}}{\omega_{s} M}
\end{array}\right.
$$

The structure of vector control for RSC is illustrated in Figure 8.

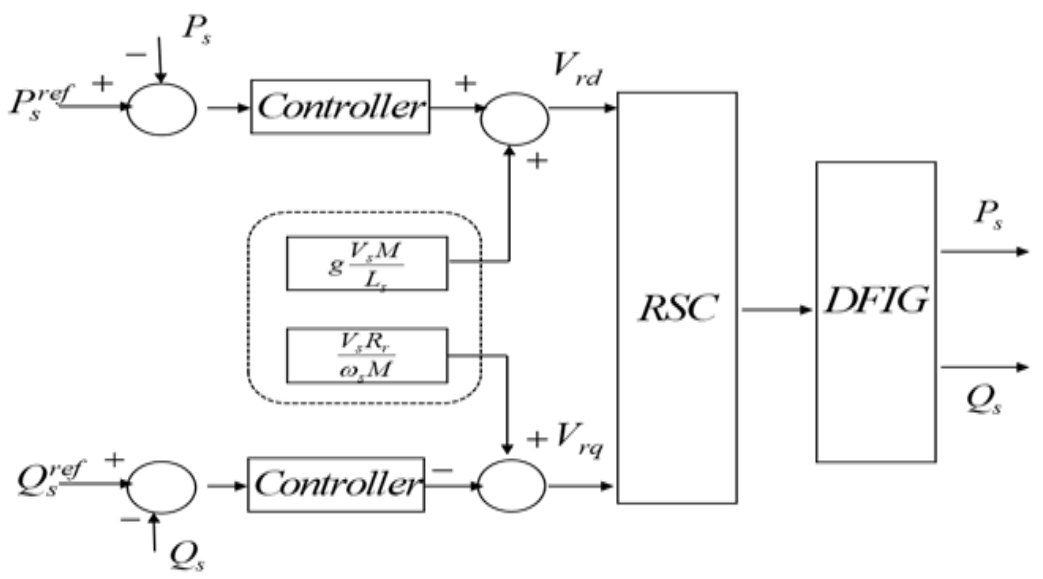

Figure 8. Block diagram of the indirect vector control for RSC

\subsubsection{PI controller synthesis for RSC}

This type of regulators is a combination of both proportional and integral actions. It has the effect of improving simultaneously the steady and the transient states [25]. To control the machine side converter by a PI controller, we have chosen the structure shown in Figure 9.

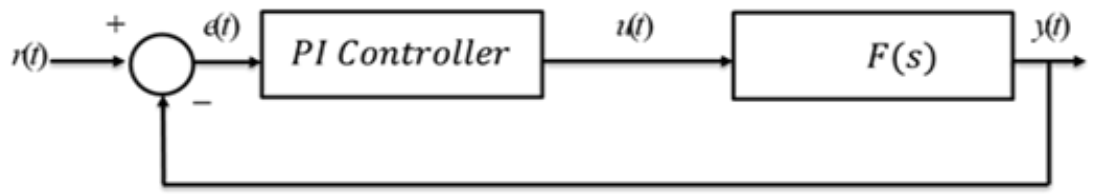

Figure 9. A typical PI controller structure

$$
F(s)=\frac{V_{S} M}{R_{r} L_{s}+s L_{s} L_{r} \sigma}
$$

The transfer function of a PI regulator is given by the following equation:

$$
C(s)=k_{p}+\frac{k_{i}}{s}
$$

The open loop transfer function is given by:

$$
G(s)=C(s) \cdot F(s)=\frac{\left(s+\frac{k_{i}}{k_{p}}\right) \frac{V_{s} M}{L_{s} L_{r} \sigma}}{\frac{s}{k_{p}}\left(s+\frac{R_{r}}{L_{r} \sigma}\right)}
$$


To compensate the zero of the transfer function we choose:

$$
\frac{k_{i}}{k_{p}}=\frac{R_{r}}{L_{r} \sigma} \Rightarrow G(s)=\frac{1}{\tau_{r} s} \text { and } \tau_{r}=\frac{L_{s} L_{r} \sigma}{k_{p} V_{s} M}
$$

The closed loop transfer function can be expressed as:

$$
H(s)=\frac{1}{1+\tau_{r} s}
$$

$\tau_{r}$ designates the time constant of the system. So the terms $k_{p}$ and $k_{i}$ are given by:

$$
\left\{\begin{array}{l}
k_{p}=\frac{L_{s} L_{r} \sigma}{\tau_{r} V_{S} M} \\
k_{i}=\frac{L_{s} R_{r}}{\tau_{r} V_{S} M}
\end{array}\right.
$$

\subsubsection{RST controller synthesis for RSC}

The chosen controller module is as follows [20]:

$$
\left\{\begin{array}{c}
A(p)=a_{1} p+a_{0} \\
B(p)=b_{0} \\
D(p)=d_{3} p^{3}+d_{2} p^{2}+d_{1} p+d_{0} \\
R(p)=r_{1} p+r_{0} \\
S(p)=s_{2} p^{2}+s_{1} p+s_{0}
\end{array}\right.
$$

In accordance with the strategy of placing robust poles, the degree of the polynomial D requires us to place three poles. This polynomial is first decomposed into a product of two polynomials $\mathrm{C}$ and $\mathrm{F}$.

$$
D=C . F=\left(p+\frac{1}{T_{c}}\right)\left(p+\frac{1}{T_{f}}\right)^{2}
$$

Let's put $P_{c}=-\frac{1}{T_{c}}$ and $P_{f}=-\frac{1}{T_{f}}$

$$
\left\{\begin{array}{c}
P_{c}=5 P_{a}=5 \frac{L_{s} L_{r}}{L_{s} L_{r}-M^{2}} \\
T_{c}=\frac{1}{P_{c}} \\
T_{f}=\frac{1}{3} T_{c}
\end{array}\right.
$$

To speed up the system, we are taking the following measures:

$$
D=\left(p-5 P_{a}\right)\left(p-15 P_{a}\right)^{2}
$$

From equations (20) and (23), we deduce the coefficients of the polynomial D which are related to the coefficients of $\mathrm{R}$ and $\mathrm{S}$ by Sylvester's matrix. In this way, we can derive the parameters of the RST controller in the following way:

Design and investigations of MPPT strategies for a wind energy conversion system ... (Bouchaib Rached) 


$$
\left\{\begin{aligned}
d_{3}=a_{1} s_{2} & \rightarrow s_{2}=\frac{d_{3}}{a_{1}} \\
d_{2}=a_{1} s_{1} & \rightarrow s_{1}=\frac{d_{2}}{a_{1}} \\
d_{1}=a_{0} s_{1}+b_{0} r_{1} & \rightarrow r_{1}=\frac{d_{1}-a_{0} s_{1}}{b_{0}} \\
d_{1}=b_{0} r_{0} & \rightarrow r_{0}=\frac{d 1}{b_{0}} \\
T & =r_{0}
\end{aligned}\right.
$$

\subsubsection{Fuzzy logic controller synthesis for RSC}

By using equation 10, the rotor current references can be derived as follows:

$$
\left\{\begin{array}{l}
I_{r q}^{r e f}=-P_{s}^{r e f} \cdot \frac{L_{s}}{\omega_{s} M \Phi_{s d}} \\
I_{r d}^{r e f}=-Q_{s}^{r e f} \cdot \frac{L_{S}}{M V_{s}}+\frac{\Phi_{s d}}{M}
\end{array} \text { and } P_{s}^{r e f}=T_{e m}^{r e f} \omega_{s}\right.
$$

where $T_{e m}^{r e f}$ is the electromagnetic reference torque deduced from the MPPT strategy. The FLC control structure for RSC is depicted in Figure 10.

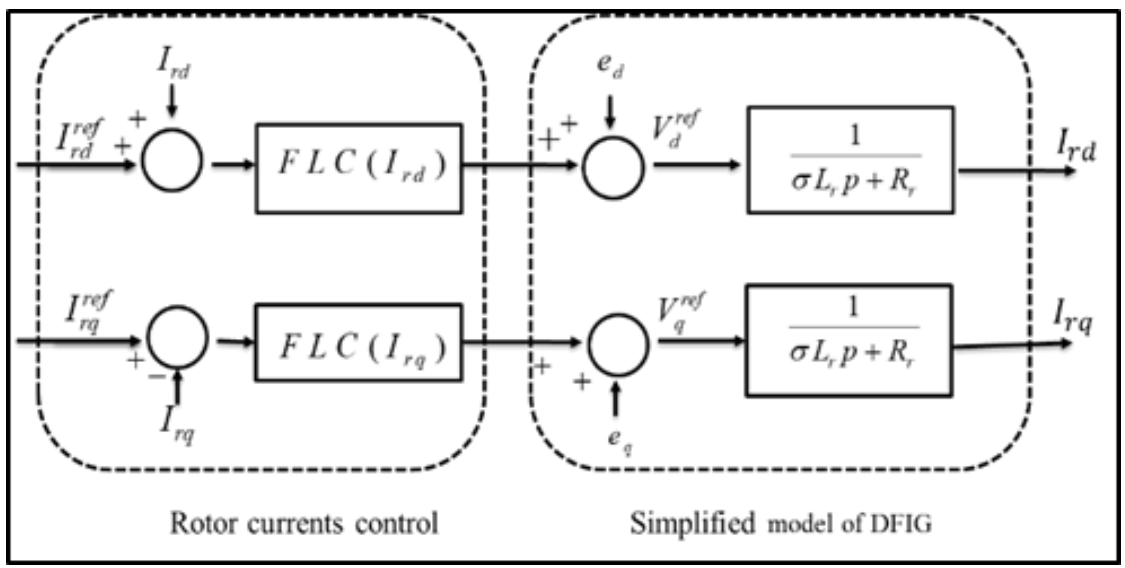

Figure 10. FLC Controller structure for RSC

\section{RESULTS AND ANALYSIS}

In this section, simulation results are presented for the studied system. The proposed model is implemented in MATLAB/Simulink. To show the performance of the control strategies studied in this work, namely FLC, RST controller, and PI controller, we have performed several tests. These tests are carried out under the following conditions: Power setpoint variation; Speed variation: at $\mathrm{t}=8[\mathrm{~s}], \rightarrow 2: 150[\mathrm{rd} / \mathrm{s}] \rightarrow 170$ $[\mathrm{rd} / \mathrm{s}]$; DFIG parameter variation: $\mathrm{t}=12[\mathrm{~s}], \mathrm{Rr} \rightarrow 2 * \mathrm{Rr}$. The following WECS parameters are used for a simulation [21, 6]: $\mathrm{Rs}=0.012 \Omega ; \mathrm{Rr}=0.021 \Omega ; \mathrm{Ls}=0.0137 \mathrm{H} ; \mathrm{Lr}=0.0136 \mathrm{H} ; \mathrm{M}=0.0135 \mathrm{H} ; \mathrm{J}=0.175 \mathrm{~kg} . \mathrm{m}^{2}$; $\mathrm{K}=0.0024 \mathrm{~N} / \mathrm{rd} / \mathrm{s} ; \mathrm{P}=2$.

\subsection{Reference tracking}

To better appreciate the differences between the proposed controls, the first series of simulations are carried out to test the performance in reference tracking. The Power coefficient with MPPT is illustrated in Figures 11 and 12. The speed of the generator is shown in Figures 13-15. The stator powers are depicted in Figures 16-18. 


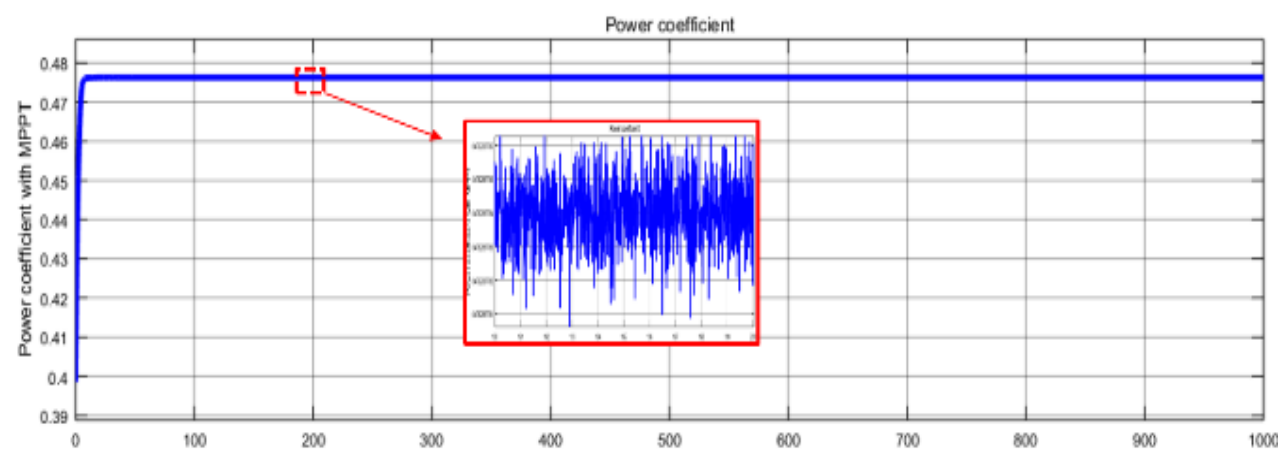

Figure 11. Power coefficient with MPPT (PI)

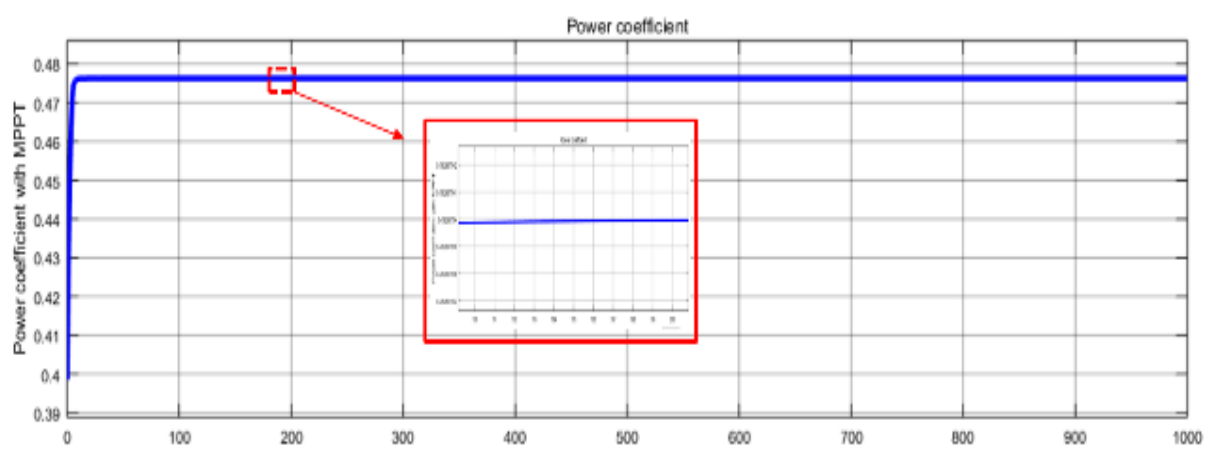

Figure 12. Power coefficient with MPPT (FLC)

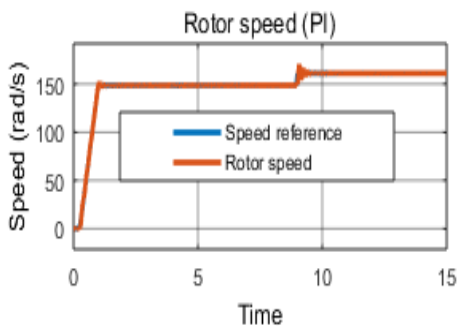

Figure 13.Speed response (PI)

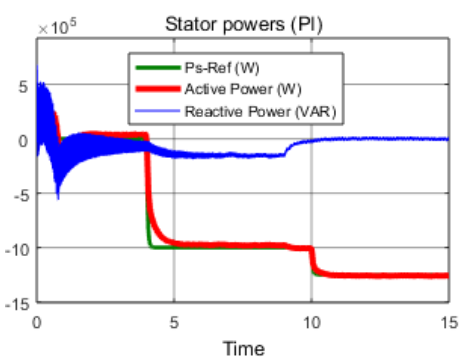

Figure 16. Power response (PI)

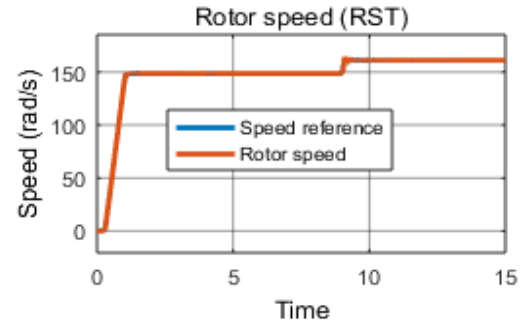

Figure 14. Speed response (RST)

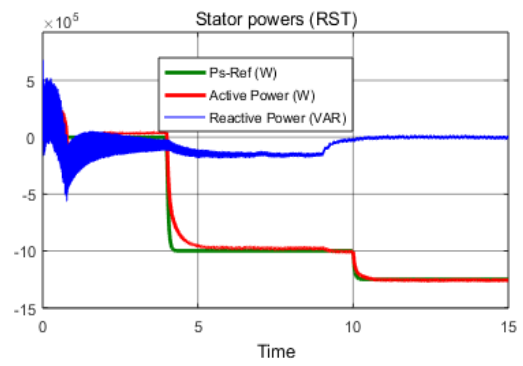

Figure 17. Power response (RST)

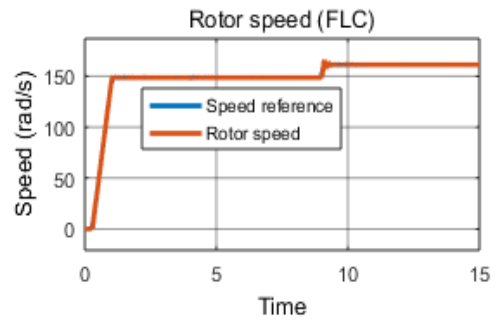

Figure 15. Speed response (FLC)

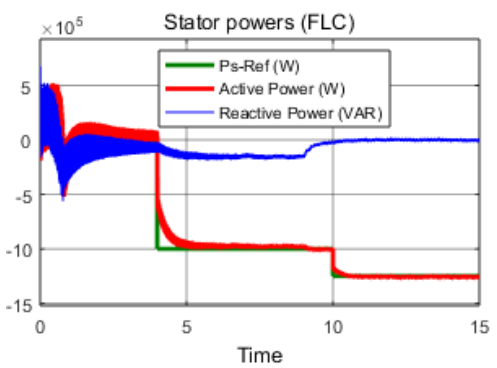

Figure 18. Power response (FLC)

MPPT controllers track the optimum power point at varying wind speeds, keeping the power coefficient at its maximum value Cpmax $=0.476$. Based on the simulation results, the FLC method reaches a steady state with a neglected error. The PI controllers show remarkable oscillations in the steady state. According to Figure 13 to 15, the response time of the PI and FLC controllers is better than the RST method, 
but at the same time, a significant overshoot is observed for the PI controller. Besides, for the powers (Figure 16 to 18): the fuzzy controller has a faster response time and a faster transient response compared to the RST controller.

\subsection{Robustness test of the proposed commands}

To test the robustness of the proposed control strategies we have introducing a variation in the parameters of the generator, such as variation of $50 \%$ in the rotor resistance $(\mathrm{Rr})$ introduced at $\mathrm{t}=12$. To test the robustness of the proposed controls and its sensitivity to parametric variations of the machine, the value of the rotor resistance has been varied as mentioned at the beginning of this section. The results in Figure 21 show that the FLC is less sensitive to parametric variations compared to PI see Figure 19 and RST see Figure 20 controls. It can be seen that the stator powers always follow their references. However, an increase in power fluctuations, as shown in Figure 19, is observed in the case of the PI controller.

According to results, the fuzzy controller has a clear advantage: Fewer oscillations at start-ups and during setpoint changes. The peaks of disturbances are much less significant with the FLC in particular. Figures 22 and 23 show the waveform of the currents for the FLC. The current has a sinusoidal waveform, in both the stator and the rotor circuit. As well, the amplitude and frequency of the rotor current vary with the speed of the generator. Very good quality of the currents under the proposed control can also be observed.

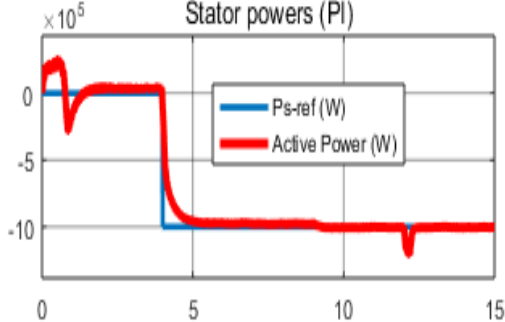

Figure 19. Power response (PI)

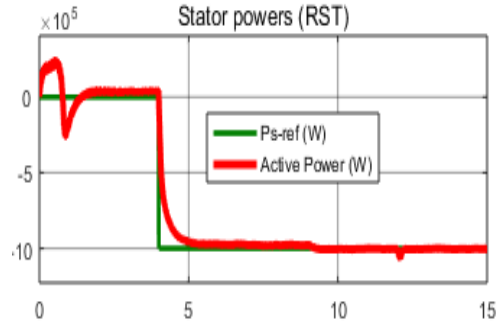

Figure 20. Power response (RST)

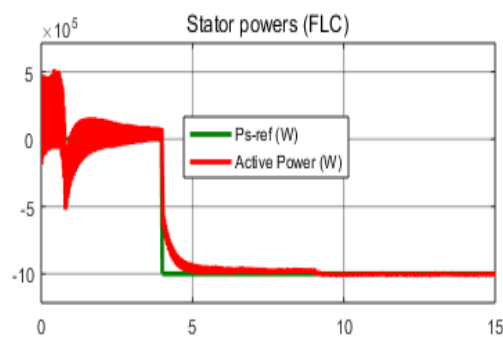

Figure 21. Power response (FLC)

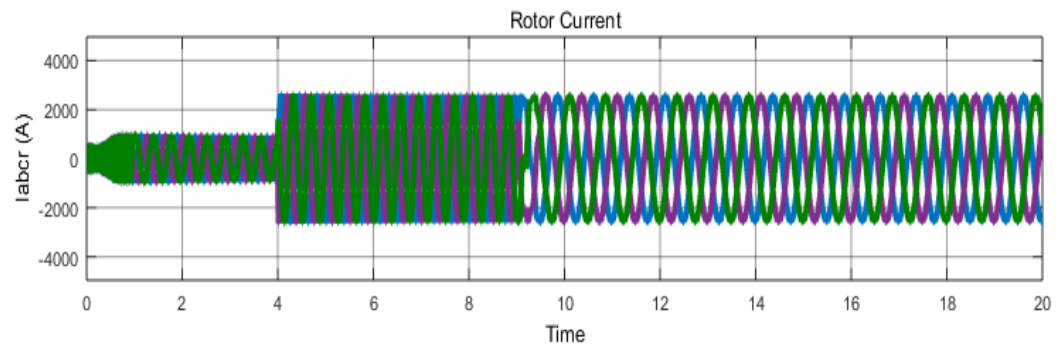

Figure 22. Rotor current response

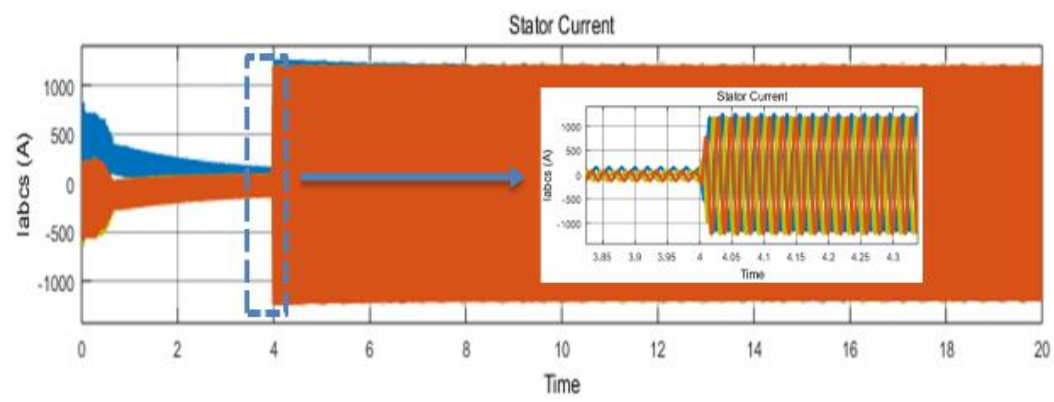

Figure 23. Stator current response

\section{CONCLUSION}

This work has been devoted to the study, modelling and research of robust control laws for a DFIG-based wind energy conversion and production system. For this reason, the different components of 
our system have been studied and modelled. The control laws and control strategies, namely fuzzy logic control, RST controllers, and classical PI control have been designed to ensure that the wind turbine can operate over a wide range of wind speeds and to get the maximum possible power out of it.

The results show that the FLC presents a better performance compared to conventional PI and RST controllers, which makes the fuzzy controller an acceptable choice for wind energy conversion systems requiring precisely tuning and less sensitive to external disturbances and parametric variations. The main interest of fuzzy logic control lies in its ability to control a system without depending on its parameters. Its effectiveness is proven when the modelling of a system is difficult, which is the case of our studied system.

\section{REFERENCES}

[1] I. Colak, et al., "Critical aspects of wind energy systems in smart grid applications," Renewable and Sustainable Energy Reviews, vol. 52, pp. 155-171, Dec 2015.

[2] Y. Nakanishi, et al., "Wind power generation," in Y. Kato, et al. (eds), "Energy Technology Roadmaps of Japan," Springer, Tokyo, pp. 307-322, 2016.

[3] D. Rekioua, "Wind Power Electric Systems: Modeling, Simulation and Control," Springer-Verlag London, 2014.

[4] Y. Baala and S. Bri, "Torque estimator using MPPT method for wind turbines," International Journal of Electrical and Computer Engineering (IJECE), vol. 10, no. 2, pp. 1208-1219, 2020.

[5] I. El Karaoui et al., "Robust power control methods for wind turbines using DFIG-generator," International Journal of Power Electronics and Drive System (IJPEDS), vol. 10, no. 4, pp. 2101-2117, 2019.

[6] A. Merabet, "Adaptive sliding mode control for wind energy experimental system," Energies, vol. 11, no. 9, pp. 1-14, 2018.

[7] M. Madark, et al., "A new induction motor adaptive robust vector control based on backstepping," International Journal of Electrical and Computer Engineering (IJECE), vol. 7, no. 4, pp. 1983-1993, 2017.

[8] B. Rached, et al., "DSP in the Loop Implementation of a Backstepping Controller for Wind Energy Conversion System Based on a Doubly Fed Induction Generator Connected to Grid," International Journal on Energy Conversion (IRECON), vol. 7, no. 4, p. 136, 2019.

[9] O. El Maguiri, et al., "Backstepping nonlinear control to maximize energy capture in a variable speed wind turbine," International Journal of Electrical and Computer Engineering (IJECE), vol. 9, no. 6, pp. 4758-4766, 2019.

[10] Hassan S., et al., "PSO-Backstepping controller of a grid connected DFIG based wind turbine," International Journal of Electrical and Computer Engineering (IJECE), vol. 10, no. 1, pp. 856-867, 2020.

[11] O. Radouane and M. Rachidi, "Adaptive Input-Output Feedback Linearization Control of Doubly-Fed Induction Machine in Wind Power Generation," International Review of Automatic Control, vol. 12, no. 1, p. 11, 2019.

[12] I. Munteanu, et al., "Optimal control of wind energy systems: towards a global approach," Springer-Verlag London, 2008.

[13] P. M. M. Bongers, "Modeling and Identification of Flexible Wind Turbines and A Factorizational Approach to Robust Control Design," Thesis, TU Delft, 1994.

[14] B. Beltran, et al., "Sliding Mode Power Control of Variable Speed Wind Energy Conversion Systems," 2007 IEEE International Electric Machines \& Drives Conference, Antalya, pp. 943-948, 2007.

[15] B. Rached, et al., "Fuzzy Logic Control for Wind Energy Conversion System based on DFIG," in 2019 International Conference on Wireless Technologies, Embedded and Intelligent Systems (WITS), pp. 1-6, 2019.

[16] B. Rached, et al., "Power Control of a Wind Energy Conversion System based on a Doubly Fed Induction Generator," in Proceedings of the Third International Conference on Computing and Wireless Communication Systems, pp. 1-6, 2019.

[17] F. Senani, et al., "A Complete Modeling and Control for Wind Turbine Based of a Doubly Fed Induction Generator using Direct Power Control," International Journal of Power Electronics and Drive Systems (IJPEDS), vol. 8, no. 4, pp. 1954-1962, 2017.

[18] J. Trivedi and T. Agarwal, "Controlling and Analysis of Variable Wind Speed Turbine with DFIG Using Fuzzy Logic Controller," IOSR Journal of Electrical and Electronics Engineering (IOSR-JEEE), vol. 12, no. 5, pp. 21-28, 2017.

[19] W. O. Amor, et al., "Study of a Wind Energy Conversion Systems Based on Doubly-Fed Induction Generator," International Review on Modelling and Simulations, vol. 7, no. 4, p. 619, Aug 2014.

[20] B. Rached, et al., "Control Strategies for DFIG based on Wind Energy Conversion System using RST and Fuzzy Logic Controllers," 2019 International Conference of Computer Science and Renewable Energies (ICCSRE), pp. 1-6, 2019.

[21] A. Dida and D. Benattous, "A complete modelling and simulation of DFIG based wind turbine system using fuzzy logic control," Frontiers in Energy, vol. 10, no. 2, pp. 143-154, Jun 2016.

[22] D. C. K. Reddy, et al., "Design of Hybrid Solar Wind Energy System in a Microgrid with MPPT Techniques," International Journal of Electrical and Computer Engineering (IJECE), vol. 8, no. 2, pp. 730-740, 2018.

[23] E. Lotfi, et al., "DSP implementation in the loop of the vector control drive of a permanent magnet synchronous machine," in Proceedings of the International Conference on Computing and Wireless Communication System, pp. 1-7, 2017.

[24] O. P. Bharti, et al., "Controller Design for DFIG Driven by Variable Speed Wind Turbine Using Static Output Feedback Technique," Engineering, Technology and Applied Science Research, vol. 6, no. 4, pp. 1056-1061, 2016.

[25] M. Elhaissouf, et al., "DSP Implementation in the Loop of the Indirect Rotor Field Orientation control for the Three-Phase Asynchronous Machine," in Proceedings of the 2nd International Conference on Computing and Wireless Communication Systems - ICCWCS'17, pp. 1-7, 2017. 